\title{
Update on Diagnosis of Childhood Acute Lymphoblastic Leukemia (ALL) in Indonesia
}

\author{
Adhitya Bayu Perdana ${ }^{1}$, Fahreza Saputra ${ }^{1}$, Mururul Aisyi* ${ }^{1,2}$ \\ ${ }^{1}$ Research and Development Department, Dharmais Cancer Hospital - National Cancer Center, Jakarta, Indonesia \\ 2 Pediatric Hematology-Oncology Department, Dharmais Cancer Hospital - National Cancer Center, Jakarta, Indonesia
}

Childhood cancer has been a global public health scourge with considerably escalating incidence each year [1]. Although the incidence is relatively lower compared to adult malignancies, it remains the leading cause of disease-related death in children. The most frequent childhood cancer is acute lymphoblastic leukemia (ALL) with an annual incidence of 3.5 per 100,000 children in the United States [2]. Similarly, in Indonesia, ALL has the highest number of cancer cases in children [3]. The total incidence of ALL in Indonesia reaches 2.5-4.0 per 100,000 children with an estimated 2,000-3,200 annually [4]. Because of its high incidence and curability, ALL is a logical initial objective for childhood cancer program developments in Indonesia.

As an indicator of successful treatment of childhood ALL, the 5-year survival rate shows contrasting figures between high-income (HIC) and lower-middle-income countries (LMIC). In the United States and most European countries, the survival rates are approximately $90 \%$ and $85 \%$ respectively. However, in Southeast Asian countries, the highest 5-year survival rate for children aged 0 to 14 was reported in Malaysia (69.4\%), followed by Thailand (55.1\%) [5]. Furthermore, more unfavorable results were reported in Indonesia. Studies from Dharmais Cancer Hospital and Dr. Sardjito Hospital reported the 5-year survival rate of $28.9 \%$ and $31.8 \%$ respectively $[6,7]$.

The outcome difference between Indonesia and other countries is probably due to the high rate of relapse occurrence and toxic death during the treatment. Some studies revealed the factors that affecting the worst outcome of childhood ALL in LMIC include inadequate and delayed diagnosis, limited healthcare access, treatment abandonment, and suboptimal supportive care [8]. As pediatric oncologists in HIC have become more effective at treating childhood ALL, much of the research attempts concentrated on the risk stratification of the patients. The term "risk stratification" is used to allocate the patients into various risk groups based on the notable prognostic features for specific treatment administration. Patients with a high-risk assessment could be targeted for more aggressive treatments, while patients with lower risk could be treated less intensively to avoid the side effects and toxicities [9].

In Indonesia, risk stratification strategy encompasses clinical-hematologic parameters (age, leukocyte count, extramedullary involvement), and conventional morphological examination. These assessments represent the first step in the diagnostic pathway of ALL. Though helpful, in certain cases, the residual leukemic cells might be undetectable under bone marrow morphology examination. This led to more underdiagnosed cases, thus more patients were subjected to inadequate treatment. Fortunately, immunophenotyping is currently applied to improve the diagnosis of childhood ALL by grouping the patients based on the aberrant expression of leukemic cell antigen, even though its application is only available in several centers including Dharmais Cancer Hospital. The BCR-ABL1 fusion gene examination by PCR-based techniques has also routinely been implemented to predict the poor outcome since it was detected in $12 \%$ of childhood ALL patients [10].

However, the current above-mentioned strategy is insufficient to solve the accuracy of risk stratification of childhood ALL. In HIC, childhood ALL are classified by more comprehensive examination involving morphology, immunophenotyping, cytogenetics, and molecular techniques. The approach to classifying prognosis and to personalize treatment based on the underlying genetic biology has already implemented for understanding the pathogenesis of childhood ALL. According to studies, the molecular features of childhood ALL have been shown to have a significant prognostic value [11], and the survival rate was improved when genetic examinations are applied [12].

In recent years, high-resolution array-based genomic technologies have revolutionized the understanding of the genetic basis of childhood ALL. Several biomarkers have successfully been identified that are provenly associated with poor prognosis in childhood ALL, including the deletion/mutation of IKZF1 (IKAROS), CDKN2A, ETV6, EBF1, JAK2, and many more [13]. The majority of these genetic changes were originally identified by sophisticated methods such as single nucleotide polymorphism (SNP) arrays, gene expression profiling (GEP), array-based comparative genomic hybridization $(\mathrm{aCGH})$, and more recently next-generation sequencing (NGS) [14]. Despite being highly sensitive for detection of multiple copy number changes, these approaches are not feasible for routine diagnostic use in LMIC which requires significant 
financial investment. Therefore, molecular techniques that suit available resources and infrastructure should be developed in LMIC, and most importantly the cost should be affordable for patients.

One feasible method is Multiplex Ligation-dependent Probe Amplification (MLPA). MLPA is a rapid multiplex PCR-based technique that enables the comparative analysis of multiple mutation spots [15]. MLPA provides a low-cost, simple alternative to array-based techniques for much routine clinical practice, even though it is unsuitable for whole-genome analysis. Furthermore, one benefit compared to other quantitative PCR-based techniques is that MLPA allows 50 or more different genomic DNA to be analyzed in a single tube reaction. Several studies have demonstrated the implementation of specific MLPA probe mixes for hematological malignancies, including ALL, chronic lymphocytic leukemia (CLL), and myelodysplastic syndrome (MDS). These studies have also shown the sensitive and accurate identification of clinically significant diseasespecific copy number changes [16].

Currently, MLPA has been established as a routine diagnostic of childhood ALL patients in Dharmais Cancer Hospital by a research-based service setting. It reliably detects small focal deletions, even from the low amount of specimens. In general, the results demonstrated the concordance between mutated genes reported in highrisk patients (deletion of IKZF1, CDKN2A, CDKN2B, PAX5). These findings surely can guide the doctors in Dharmais Cancer Hospital to assign the specific patients for the intensive treatment protocol, which is expected to increase the patient's survival. Therefore, concerning the future clinical application, the inclusion of mutation status by MLPA for childhood ALL risk stratification should be widely promoted to a large health community, especially the Indonesian Pediatric Society, which views this as a consideration for refinement of standard diagnosis protocol for childhood ALL in Indonesia.

Corresponding author:

Mururul Aisyi

Pediatric Hematology-Oncology Department, Dharmais Cancer

Hospital - National Cancer Center, Jakarta, Indonesia

aci97nabil@yahoo.com

\section{REFERENCES}

1. Fung A, Horton S, Zabih V, et al. Cost and costeffectiveness of childhood cancer treatment in lowincome and middle-income countries: a systematic review. BMJ Glob Heal. 2019;4(5):1-13.

2. Howlader N, Noone AM, Krapcho M, et al. SEER Cancer Statistics Review, 1975-2017: Childhood cancer by site [internet]. Bethesda: National Cancer Institute, 2019 [cited 2020 Nov 13]. Available from: https:// seer.cancer.gov/csr/1975_2017/results_merged/ sect_28_childhood_cancer.pdf

3. Suzanna E, Sirait T, Rahayu PS, et al. Registrasi Kanker Berbasis Rumah Sakit di Rumah Sakit Kanker "Dharmais" - Pusat Kanker Nasional, 1993-2007. Indones J Cancer. 2007;6(4):181-205.

4. Wolley NGA, Gunawan S, Warouw SM. Perubahan status gizi pada anak dengan leukemia limfoblastik akut selama pengobatan. e-CliniC. 2016;4(1).

5. Pui $\mathrm{C}-\mathrm{H}$, Yang JJ, Bhakta N, Rodriguez-Galindo C. Global efforts toward the cure of childhood acute lymphoblastic leukemia. Lancet Child Adolesc Heal. 2018;2(6):440-454.

6. Simanjorang C, Kodim N, Tehiteru E. Perbedaan kesintasan 5 tahun pasien leukemia limfoblastik akut dan leukemia mieloblastik akut pada anak di Rumah Sakit Kanker Dharmais, Jakarta, 1997-2008. Indones J Cancer. 2013;7(1):15-21.

7. Mulatsih S, Hariningrum A, Purwanto I. Implementing Yogyakarta Pediatric Cancer Registry for 16 Years: a report of hospital-based childhood cancer registry Sri. Pediatr Indones. 2019;59(4):188-94.

8. Abboud MR, Ghanem K, Muwakkit S. Acute lymphoblastic leukemia in low and middleincome countries: Disease characteristics and treatment results. Curr Opin Oncol. 2014;26(6):650-5.

9. Settin A, Al Haggar M, Al Dosoky T, Al Baz R, Abdelrazik $N$, Fouda $M$, et al. Prognostic cytogenetic markers in childhood acute lymphoblastic leukemia: Cases from Mansoura, Egypt. Hematology. 2006;11(5-6):341-9.

10. Aisyi M, Lestari P, Nadliroh $S$, et al. The profile of BCRABL1 fusion gene in childhood leukemia at "Dharmais" Cancer Hospital. Indones J Cancer. 2020;14(3):86-90.

11. Vrooman LM, Silverman LB. Childhood acute lymphoblastic leukemia: Update on prognostic factors. Curr Opin Pediatr. 2009;21(1):1-8.

12. Evans WE, Crews KR, Pui C-H. A health-care system perspective on implementing genomic medicine: Pediatric acute lymphoblastic leukemia as a paradigm. Clin Pharmacol Ther. 2013 Aug 17;94(2):224-9.

13. Chiaretti S, Zini G, Bassan R. Diagnosis and subclassification of acute lymphoblastic leukemia. Mediterr J Hematol Infect Dis. 2014;6(1):e2014073.

14. Biondi A, Cazzaniga G. Novel clinical trials for pediatric leukemias: lessons learned from genomic analyses. Hematology Am Soc Hematol Educ Program. 2013;2013:612-9

15. Schouten JP, McElgunn CJ, Waaijer R, et al. Relative quantification of 40 nucleic acid sequences by multiplex ligation-dependent probe amplification. Nucleic Acids Res. 2002;

16. Konialis C, Savola S, Karapanou S, et al. Routine application of a novel MLPA-based first-line screening test uncovers clinically relevant copy number aberrations in haematological malignancies undetectable by conventional cytogenetics. Hematology. 2014;19(4):217-24. 